Background Burns from hot drinks are common and preventable amongst children under 5 years.

Methods The 3-month SafeTea campaign aimed to prevent hot drink scalds and improve burns first aid using social media, and a website hosting downloadable resources and videos. Key messages were disseminated on Twitter, Facebook and MumsNet to parents/caregivers. Evaluation included social media metrics, Google Analytics, quantitative and qualitative results from a sample survey of 500 professionals who received hard copies of SafeTea resources on request (posters, fliers, fridge magnets, stickers and activity packs).

Results SafeTea benefited from being launched on National Burns Awareness Day 2019, and from the two 'case studies' that attracted media interest. of an estimated 9,550 Facebook users per day, 84\% were women between 25 and 44 years old. A scald prevention video was viewed 154,000 times and the first aid video 245,000 times. SafeTea impressions on Twitter totalled 196,400 , with an average engagement rate of $0.78 \%$.

19,059 unique webpages were viewed, and the majority of social media referrals to the website $(96.5 \%)$ originated from Facebook.

Qualitative feedback from parents relating to the two campaign videos was very positive, and $87 \%$ professionals surveyed rated the campaign materials as 'excellent' or 'good'.

Conclusion Social media is an effective way to deliver injury prevention to parents and childcare professionals.

Learning Outcomes Linking burn prevention messages to first aid advice was effective. Burns awareness day gave SafeTea invaluable publicity and boosted Facebook and Twitter engagement. Social media analytics suggested that the campaign could have been shorter.

\section{C.006 THE CURRENT IN THE HOT CROSS BUN}

Ruth Barker*. Queensland Injury Surveillance Unit, Brisbane, Australia

10.1136/injuryprev-2021-safety. 161

Context Button batteries (BBs) cause caustic injury if ingested or inserted with severe/fatal injuries predominantly affecting toddlers. They are ubiquitous, seemingly innocuous household items that power a myriad of products, from the essential to the inane. However, limiting exposure and access to BBs encompasses more than the domestic setting and requires much more than 'buyer education'.

Process Understanding this issue has required collaborative sharing of data and epidemiological knowledge between Poisons services, clinicians, researchers, regulators, Coronial staff and families. In 2017, The Australian Paediatric Surveillance Unit (APSU) began collating severe injuries related to BBs in children under 16 years, collecting data on the mode of access and product associated with the BB injury.

Analysis Data complied through APSU, case follow up and other Coronial/incident reports shows that BBs are frequently not purchased by the injured child's family. They are often promotional giveaways, free medical devices, gifts or found items. If they are purchased by the child's family, the purchaser was often unaware that there was a $\mathrm{BB}$ or that the $\mathrm{BB}$ was not secured/loose in the packet. In many instances, the source of the $\mathrm{BB}$ remains unknown.
Outcomes Detailed case analysis with a product safety/regulatory lens has scotched the notion that better buyer education in isolation will be effective in mitigating the risk of severe injury.

Learning Outcomes Cross-silo collaboration has allowed a more complex and complete understanding of this issue facilitating legislative change to make BBs packaging and products child resistant.

\section{D - Data, March 25, 2021}

\section{D.001 EFFECTIVE USE OF AMBULANCE TRANSPORT DATA FOR INJURY PREVENTION IN JAPAN}

Yoko Shiraishi*. Japan Institution For Safe Communities, Osaka City, Japan

\subsection{6/injuryprev-2021-safety. 162}

Background In Japan, the safe Community (SC) Program, the injury prevention strategies based on the seven indicators have been adapted to communities. Considering that SC programs should be scientifically developed based on evidence, Japanese communities must overcome the disadvantage of absence of the national injury surveillance system. To solve this situation, this study aims to develop the injury surveillance function by making the use of ambulance transport data.

Methods Injury cases were extracted from the ambulance transport dataset (ATD) in Kameoka City in 2010 to 2019, then longitudinally analyzed to see what cause injuries and how to be prevented.

Results The main purpose of ATD is to verify and improve efficient transportation of patients to the medical institutions. Therefore, the information which is useful to prevent injuries is partially found only in the description about the patients on arrival.

Conclusion ATD data doesn't contain all the information to prevent injuries and it requires several steps to make it possible to identify factors which cause injuries and the develop injury prevention programs. However, we found that it is still most useful data with which we can get information which cannot get in other existing data collection systems in Japan.

Learning Outcomes Considering that ATD contains the more information which can be used to develop effective intervention of injury prevention than any other datasets in Japan, it is very important to develop the system in which the information related to injury occurrence can be systematically extracted and analyzed to develop effective intervention.

\section{D.002 CODING AND MAPPING INJURY DIAGNOSES AND SEVERITIES FOR TRAUMA REGISTRIES AND RESEARCH}

Mark Zonfrillo*. Alpert Medical School of Brown University, Providence, USA

\subsection{6/injuryprev-2021-safety. 163}

Context Injury diagnosis and severity coding are essential for trauma registries and epidemiologic research. Local and national governments, hospitals, and academic institutions all rely on injury diagnoses in order to optimize policy, legislation, and medical care. 
Process The following lexicons will be reviewed at a highlevel: International Classification of Diseases (ICD) diagnoses and mechanism of injury codes, the International Collaborative Effort (ICE) on Injury Statistics Barell Injury Diagnosis Matrix, the Association for the Advancement of Automotive Medicine's (AAAM's) Abbreviated Injury Scale (AIS), and multiple mapping options from ICD to AIS codes for various versions of each.

Analysis and Outcomes Understanding a systematic and standardized approach to injury coding and mapping is critical to ensure methodologically rigorous and valid activities for injury registry personnel, medical providers, and researchers. There are multiple applications for injury coding and mapping including: mandates for trauma registry accreditation, informing surveillance and interventions, contributing to regional and national trauma databases, facilitating database sharing across various entities, describe community and region-specific epidemiology, guiding injury prevention prioritization efforts, facilitating the evaluation of injury prevention programs' effectiveness, and synergistic collaboration with other groups.

Learning Outcomes The audience will learn about injury coding and mapping using various, standardized lexicons.

\section{D.003 "IDEAS", USING NATIONAL DATA AS A DRIVING FORCE FOR LOCAL ACTION AND ENGAGEMENT}

Eva Vaagland*. Norwegian Safety Forum, Oslo, Norway

10.1136/injuryprev-2021-safety. 164

Context Norwegian Safety Forum is a non-profit organization, a national advocate for safety supported by the Norwegian Ministry of Health, working on three levels; projects and activities on local level, lobbying and policy work on national level, partner and contributor on International level.

National data on injuries are incomplete and difficult to access in Norway. As an advocate for safety we needed a tool to present injury data and prevention measures in an engaging way. We came up with 'IDEAS', the Injury Data Easily Accessible Solution.

Process A grant from InnoMed gave us an opportunity to cooperate with experts on information and service design. With their expertise in communication and our knowledge of available data, and best practice we developed a digital solution.

The solution is based on national data, converted to a local setting, using informative graphic combined with information on injury prevention programs. The goal is to promote local action plans.

Outcomes In February 2019 we launched the prototype. It has been tested by several communities and organizations. The feedback from the test groups was important and we could adjust and improve the solution. The feedback proved that our hypothesis was correct, and we have established a solid base for futher work and a future national solution.

Learning Easy accesesseble data introduced in a logical, comprehensible way, with a local approach, along with information on how to prevent accidents is a way to create more focus and interest for the scope of injuries and the possibilities to prevent them.
$6 \mathrm{E}$ - Mixed Bag - Injury Prevention, March 25, 2021

\section{E.001 PHYSICAL INJURIES AND BURNS AMONG REFUGEES IN LEBANON: PREVENTION, PROGRAMS, AND POLICIES}

${ }^{1}$ Samar Al-Hajj ${ }^{*}$, ${ }^{3}$ Moustafa Moustafa, ${ }^{2}$ Majed El Hechi, ${ }^{1}$ Mohamad Chahrour, ${ }^{1}$ Ali Nasrallah, ${ }^{2}$ Haytham Kaafarani. 'American University of Beirut, Van Dyck Hall, Beirut, Lebanon; ${ }^{2}$ Division of Trauma, Emergency Surgery and Surgical Critical Care, Massachusetts General Hospital, Harvard Medical School, Boston, Massachusetts, USA; ${ }^{3}$ University of Virginia, Richmond, USA

\subsection{6/injuryprev-2021-safety. 165}

Background Refugees are prone to increased risks of injury frequency and severity. In this study, we systematically quantified the prevalence of injuries and burns among refugees in Lebanon and examined injury characteristics, risk factors and outcomes.

Method We conducted a cluster-based population survey across 21 refugee camps in Lebanon from February to April 2019. We used a modified SOSAS tool to record refugees' injuries sustained in the last 12 months. We performed descriptive and multivariate regression analyses to understand the association between variables.

Results of the 1,500 refugees interviewed, 33\% sustained an injury, of which $30 \%$ were occupational injuries. Injuries caused $12 \%$ of refugees' reported deaths. Almost $18.1 \%$ of refugees $(\mathrm{N}=136)$ suffered from burns and $14.8 \%(\mathrm{~N}=111)$ suffered from other injuries (i.e. road traffic, assault). Most burns were sustained by children and caused by boiling liquid $(\mathrm{N}=61,49.6 \%)$, heat contact $(\mathrm{N}=38,30.9 \%)$ and open flame $(\mathrm{N}=17,13.8 \%)$. Injuries mainly affected extremities $(43 \%, \mathrm{p}<0.001)$ compared to head/face $(26 \%$, $\mathrm{p}<0.001)$, and occurred on the road $(29 \%)$ and in the field $(4 \%)$. Burns was more frequent to face $(34 \%, \mathrm{p}<0.001)$ compared to abdomen $(17 \%, \mathrm{p}<0.001)$ and occurred mostly inside the tent (31\%). Male gender, illiteracy and occupation were associated with increased injuries $(p<0.05)$. Almost $31.4 \%$ of injured suffered long term disability, and $6.8 \%$ required help with mobility.

Conclusion Refugees suffer from a high burden of injury with human and economic repercussions. These findings will guide the allocation of healthcare resources and the design of refugee injury prevention programs and policies.

\section{F - WHS - Program, March 25, 2021}

\section{F.001 INJURY AT WORK: HOW CAN WORKERS CONTRIBUTE TO REDUCE HARMS?}

Trang Khieu*. Worksafe NZ, Wellington, New Zealand

\subsection{6/injuryprev-2021-safety. 166}

Background Work-related injury is a major concern for business, society and community. Identifying workers' role in addressing health and safety (H\&S) risks in the workplace is key for implementing better harm prevention.

Methodology: The survey was conducted from 2014 to 2017. A total of 8489 workers in the four New Zealand high risk industries including construction, forestry, manufacturing 